A) Check for updates

Cite this: Dalton Trans., 2020, 49, 8201

Received 14th April 2020,

Accepted 26th May 2020

DOI: $10.1039 / \mathrm{d} 0 \mathrm{dt} 01864 \mathrm{c}$

rsc.li/dalton

\section{1,3,4-Azadiphospholides as building blocks for scorpionate and bidentate ligands in multinuclear complexes $\uparrow$}

\author{
Riccardo Suter, (DD *a Mona Wagner, ${ }^{a}$ Lorenzo Querci, ${ }^{a}$ Riccardo Conti, (D) a \\ Zoltán Benkő (D ${ }^{\mathrm{b}}$ and Hansjörg Grützmacher (D)*a
}

\section{Introduction}

One of the world's most famous dyes is Prussian blue, an iron cyanide complex with the formula $\left[\mathrm{Fe}(\mathrm{CN})_{6}\right]_{3} \mathrm{Fe}_{4}{ }^{1}{ }^{1}$ The different oxidation states of the iron centers in the polynuclear complex allow charge transfer processes which cause the dark blue color of the complex. Polynuclear metal complexes often show luminescence ${ }^{2}$ or even phosphorescence making them potential triplet emitters in light emitting diodes. ${ }^{3}$ Assemblies of metal complexes with unpaired electrons can form single molecule magnets. ${ }^{4-10}$ Not only small linear linkers ${ }^{11}$ such as cyanates ${ }^{12-14}$ or azides ${ }^{15}$ have been applied but also anionic rings such as triazoles, ${ }^{16}$ tetrazoles $^{17}$ or phosphorus containing heterocycles ${ }^{18}$ have been used to generate scorpionate type ligands which serve as ligands in a very broad range of metal complexes $^{19-21}$ and as components in opto-electronic materials. ${ }^{22}$ The phosphaethynolate anion (OCP) ${ }^{-}$is an excellent building block for a wide variety of organophosphorus

\footnotetext{
${ }^{a}$ Department of Chemistry and Applied Biosciences, ETH Zurich, CH-8093 Zurich, Switzerland.E-mail: hgruetzmacher@ethz.ch, riccardo.suter@bluewin.ch ${ }^{b}$ Budapest University of Technology and Economics, Szent Gellért tér 4., 1111 Budapest, Hungary

$\dagger$ Electronic supplementary information (ESI) available: Containing synthetic procedures and experimental details. CCDC 1494716, 1494717, 1494718, 1494719, 1494720, 1494721, 1494722, 1494723, 1494802, 1495143, 1495146 and 1495123. For ESI and crystallographic data in CIF or other electronic format see DOI: $10.1039 / \mathrm{d} 0 \mathrm{dt} 01864 \mathrm{c}$
}

compounds. ${ }^{23-26}$ Due to its ambident nucleophilic character, it binds to soft centers ${ }^{27-32}$ via the phosphorus atom (M$\mathrm{P}=\mathrm{C}=\mathrm{O}$ ) and hard centers via the oxygen atom ( $\mathrm{M}-\mathrm{O}-$ $\mathrm{C} \equiv \mathrm{P}) \cdot{ }^{33-39}$ Furthermore, phosphaketenes $([\mathrm{M}]-\mathrm{P}=\mathrm{C}=\mathrm{O})$ with $[\mathrm{M}]=$ main group element or transition metal fragment show a tendency to lose carbon monoxide which allows to prepare mono- and polynuclear metal phosphides..$^{23,33,40-47}$ There are very few examples which show a bridging OCP-unit between two metal centers. ${ }^{42,48-51}$ A high yield multigram synthesis of annulated oxy functionalized 1,3,4-azadiphospholides such as $\mathrm{Na}$ [1] (Scheme 1) from $\mathrm{Na}(\mathrm{OCP})$ and 2-chloropyridines was developed. ${ }^{52,53}$ These anionic heterocycles contain a OCP-functionality stabilized within the aromatic scaffold of the 1,3,4azadiphosphole and therefore no elimination of carbon monoxide is expected.

\section{Results and discussion}

In this paper, we report the use of $\mathrm{Na}[\mathbf{1}]$ as anionic building block to form tridentate scorpionate-type ligands containing low-coordinated $\lambda^{3}, \sigma^{2}$-phosphorus atoms as donor sites. The electronic properties of these polydentate ligands can be modified easily by varying the central oxophilic linker.

To form a neutral tridentate ligand, three equivalents of the azadiphospholide $\mathrm{Na}[\mathbf{1}]$ were added to the phenyl trichlorosilane $\mathrm{PhSiCl}_{3}$ in THF. The reaction mixture turned yellow 

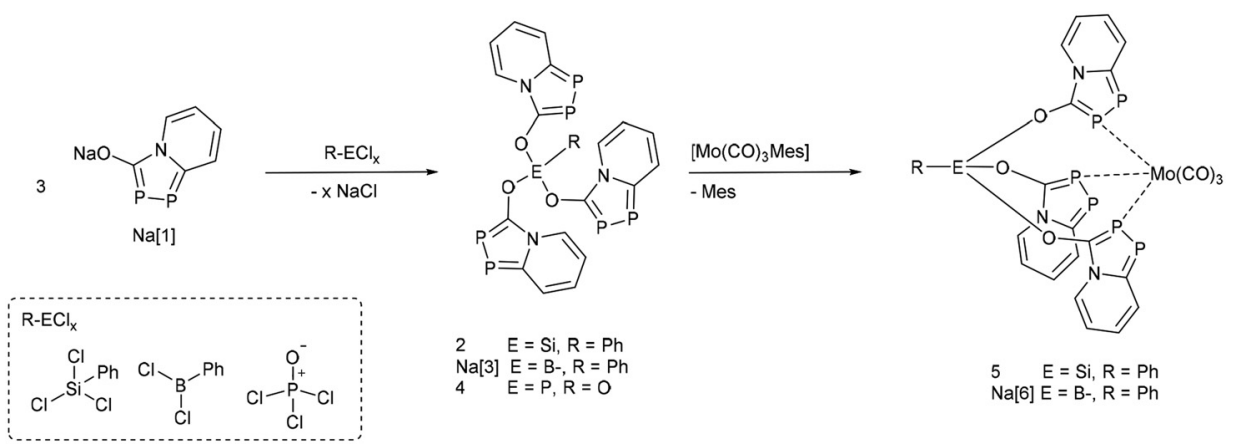

Scheme 1 Synthesis of main group substituted scorpionates 2, $\mathrm{Na}[3]$ and 4 from $\mathrm{Na}[1]$ and the corresponding molybdenum complexes 5 and $\mathrm{Na}[6]$.

immediately and a white precipitate was formed. Isolation of the pure compound 2 was possible by recrystallization. In $\mathrm{CD}_{2} \mathrm{Cl}_{2}$ as solvent, the product exhibits two doublet resonances with very similar chemical shifts $\left({ }^{31} \mathrm{P} \delta=118.8\right.$ and $123.0 \mathrm{ppm}$, ${ }^{1} J_{\mathrm{PP}}=442.3 \mathrm{~Hz}$ ). The similarly tris(substituted) but anionic boron analogue $\mathrm{Na}[3]$ has been isolated in the reaction of three equivalents of $\mathrm{Na}[\mathbf{1}]$ with $\mathrm{PhBCl}_{2}$. However, similar reactions with $\mathrm{PCl}_{3}$ only formed a mixture of products and copious amounts of a brown precipitate, which could not be identified. The reaction of three equivalents of $\mathrm{Na}[\mathbf{1}]$ with phosphoryl chloride $\mathrm{POCl}_{3}$ on the other hand formed one major product, which was unambiguously identified by X-ray crystallography as the expected tris(substituted) phosphine oxide compound 4 (Fig. 1). The ${ }^{31} \mathrm{P}\left\{{ }^{1} \mathrm{H}\right\}$-NMR spectrum in $\mathrm{CD}_{2} \mathrm{Cl}_{2}$ shows three different phosphorus resonances. The resonance for the $\mathrm{P}=\mathrm{O}$ atom is observed at low frequency $\left({ }^{31} \mathrm{P} \delta=-20.8 \mathrm{ppm}\right)$, comparable to $(\mathrm{Ph}-\mathrm{O})_{3} \mathrm{P}=\mathrm{O}\left({ }^{31} \mathrm{P} \delta=-17.3 \mathrm{ppm}\right.$ in $\left.\mathrm{CDCl}_{3}\right),{ }^{54}$ and does not show any coupling to the phosphorus atoms of the azadiphospholide substituents. The ${ }^{1} J_{\mathrm{PP}}$ coupling in the azadiphosphole ring $\left({ }^{1} J_{\mathrm{P} 1, \mathrm{P} 2}=446.5 \mathrm{~Hz}\right)$ is comparable to that in the silicon species $2\left({ }^{1} J_{\mathrm{PP}}=442.3 \mathrm{~Hz}\right)$ and significantly larger than that in the sodium salt $\mathrm{Na}[1]\left({ }^{1} J_{\mathrm{P} 1, \mathrm{P} 2}=424.7 \mathrm{~Hz}\right)$.

To study the suitability of these compounds as ligands in transition metal complexes, one equivalent of the molybdenum complex $\left[\mathrm{Mo}(\mathrm{Mes})(\mathrm{CO})_{3}\right]$ dissolved in THF was added to a solution of $2, \mathrm{Na}[3]$, or 4 , respectively. Upon standing at room temperature for 16 hours, dark yellow single crystals suit-

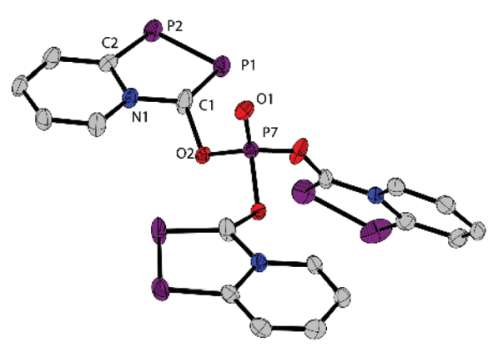

Fig. 1 Crystal structure of compound 4. Anisotropic thermal displacement ellipsoids are shown at the $50 \%$ probability level. Hydrogen atoms and the solvent molecules are omitted for clarity reasons. Average interatomic distances (Å) summarized in Table 1. able for X-ray crystal diffraction studies of the silicon complex 5 and boron species $\mathrm{Na}[\mathbf{6}]$, grew from the reaction mixtures (Fig. 2). The complexes show the expected $\kappa^{3} \mathrm{P}$-coordination mode of the tridentate ligands 2 and $\mathrm{Na}[3]$. No clean product was isolated from the reaction of $\left[\mathrm{Mo}(\mathrm{Mes})(\mathrm{CO})_{3}\right]$ with 4 .

In the next step, the use of oxophilic transition metal halides as central connecting node was tested. Therefore $\mathrm{CpTiCl}_{3}$ and three equivalents of $\mathrm{Na}[\mathbf{1}]$ were suspended in toluene to instantly form a deep purple solution. The mixture was left at room temperature for 72 hours without stirring to give a dark purple product 7 as crystalline solid. This procedure only produces a low yield due to the formation of several side products. When a large excess of $\mathrm{Na}[\mathbf{1}]$ was added to $\mathrm{CpTiCl}_{3}$, a dark green solution was obtained from which dark green crystals were isolated and identified as the dianionic hexa-substituted compound $\mathrm{Na}_{2}\left[\mathbf{8}_{\mathrm{Ti}}\right]$ (Scheme 2). In this reaction not only the chloride but also the cyclopentadienide $\left(\mathrm{Cp}^{-}\right)$became substituted by a azadiphospholide group. Both compounds, 7 and $\mathrm{Na}_{2}\left[\mathbf{8}_{\mathrm{Ti}}\right]$, have been unambiguously identified by single crystal X-ray diffraction methods and plots are shown in Fig. 5.

The titanium species $\mathrm{Na}_{2}\left[\mathbf{8}_{\mathrm{Ti}}\right]$ can be synthesized directly in the reaction of six equivalents of the sodium salt of $\mathrm{Na}[\mathbf{1}]$ with $\mathrm{TiCl}_{4}(\mathrm{THF})_{2}$. This route gives very good yields (>95\%) and pure and single crystalline material can be isolated on a multi-gram scale. The analogous dianions $\left(\mathrm{Na}_{2}\left[\mathbf{8}_{\mathbf{Z r}}\right]\right.$ and $\left.\mathrm{Na}_{2}\left[\mathbf{8}_{\mathbf{H f}}\right]\right)$ with the heavier group four metals zirconium and hafnium were synthesized using a similar procedure (ESI $\dagger$ for details).

The salts containing the heavier group four metals in the center show a significant blue shift of the longest wave absorption compared to the titanium species (Fig. 3).

Solutions of 7 are dark purple and $\mathrm{Na}_{2}\left[\mathbf{8}_{\mathrm{Ti}}\right]$ are coloured dark green, whereas the zirconium and hafnium complexes yield yellow to orange solutions, respectively. To elucidate the excitation processes, TD-DFT calculations (on the B3LYP/6$31 \mathrm{G}^{*}$ level of theory) were performed on optimized structures of the titanium compound 7 and $\left[\mathbf{8}_{\mathrm{Ti}}\right]^{2-}$ including a PCM solvent model with THF. Complex 7 exhibits an absorption maximum at $\lambda_{\max }=498 \mathrm{~nm}$ in THF, which agrees well with the calculated values. The most intense absorption of the ones at lower energies is calculated to be at $464 \mathrm{~nm}$ with weaker 


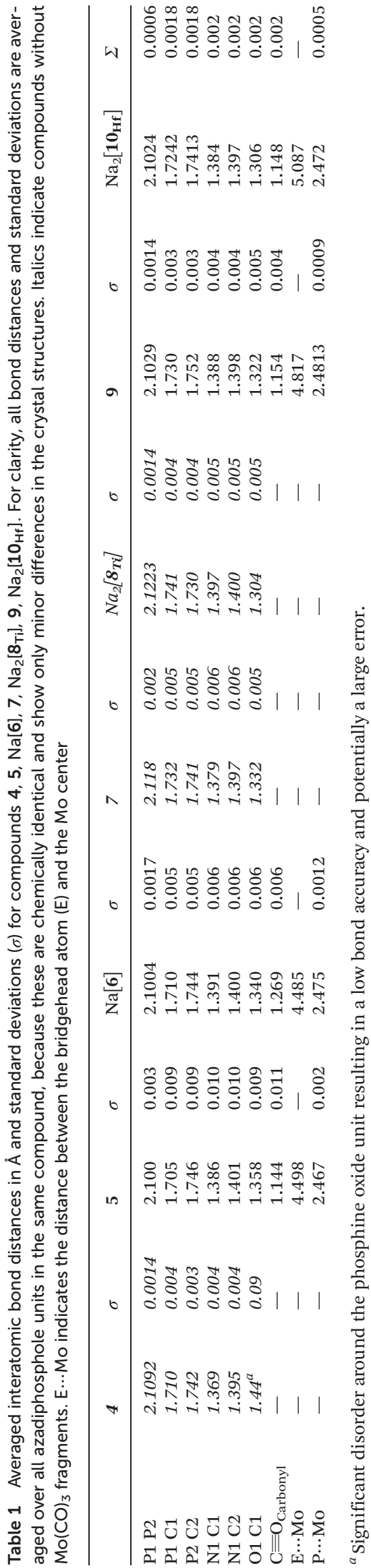

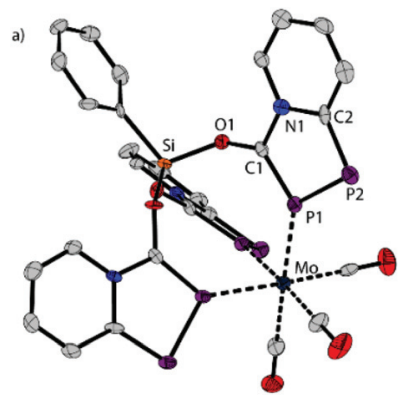

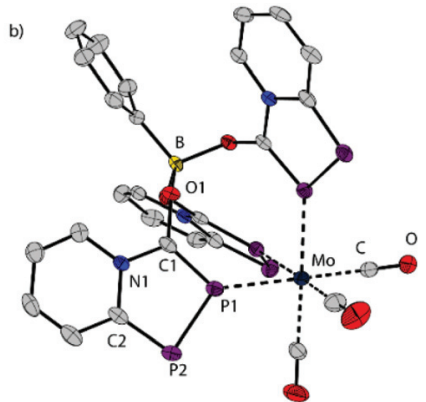

Fig. 2 Solid state structure of 5 (a) and the anion in $\mathrm{Na}$ [6] (b), anisotropic thermal displacement ellipsoids are shown at the $50 \%$ probability level. Hydrogen atoms and the sodium ion in [6] $]^{-}$are omitted for clarity. Average interatomic distances are summarized in Table 1.

absorptions up to $504 \mathrm{~nm}$. Analogously $\left[\mathbf{8}_{\mathrm{Ti}}\right]^{2-}$ possesses a $\lambda_{\max }$ of $520 \mathrm{~nm}$ in THF with a broad shoulder up to $700 \mathrm{~nm}$ in the UV-VIS spectrum (Fig. 3) which matches well with the absorptions found by TD-DFT at $\lambda_{\max }=544-547 \mathrm{~nm}$ with weaker ones up to $608 \mathrm{~nm}$. Contours of the frontier molecular orbitals for compound $\left[\mathbf{8}_{\mathbf{T i}}\right]^{2-}$ are depicted in Fig. 4 and show that the occupied orbitals are mainly ligand centered. On the other hand, the unoccupied acceptor orbitals are metal centered d-orbitals. Consequently, these absorptions are best described as ligand to metal charge transfer (LCMT) bands and the fact that these occur at rather low energies support the fact that azadiphospholides $\mathrm{Na}[\mathbf{1}]$ are electron rich molecules. A related charge transfer process was observed for the anions of the cyano-substituted azadiphospholides of $\mathrm{Na}$ [1] , which have absorption maxima ranging from $\lambda_{\max }=525$ to $596 \mathrm{~nm} .^{52}$ In these anions, the azadiphospholide acts as a donor and the cyano substituent as the electron accepting group causing strongly coloured species. The absorption maxima of the heavier group four metals dianions, $\mathrm{Na}_{2}\left[8_{\mathbf{z r}}\right]\left(\lambda_{\max }=422.5 \mathrm{~nm}\right)$ and $\mathrm{Na}_{2}\left[\mathbf{8}_{\mathbf{H f}}\right]\left(\lambda_{\max }=409.0 \mathrm{~nm}\right)$ are blue shifted compared to $\mathrm{Na}_{2}\left[\mathbf{8}_{\mathrm{Ti}}\right]$ which is explained by the lack of LCMT bands (Fig. 3 ). The reason for this are the energetically higher lying acceptor orbitals at the heavier group four metals resulting in a poor overlap with the occupied ligand orbitals.

In analogy to the reaction with compound 5, compound 7 was added to a THF solution of the molybdenum precursor complex $\left[\mathrm{Mo}(\mathrm{Mes})(\mathrm{CO})_{3}\right]$. After 24 hours dark red crystals were obtained from the reaction mixture and the product was identified as the bimetallic complex 9 (Fig. 5). Due to the low solubility in common organic solvents, no NMR spectra could be recorded but the purity of the complex was proven by elemental analysis. Reactions of $\mathrm{Na}_{2}\left[\mathbf{8}_{\mathrm{Ti}}\right]$ with two equivalents of $\left[\mathrm{Mo}(\mathrm{Mes})(\mathrm{CO})_{3}\right]$ did form an insoluble microcrystalline solid. In the IR-spectrum, two distinct CO stretching vibrations at $\nu=1925 \mathrm{~cm}^{-1}$ and $\nu=1829 \mathrm{~cm}^{-1}$ are observed indicating a similar coordination environment around the molybdenum center as observed in compounds $\mathbf{5}$ or $\mathbf{9}$, respectively. Addition of two equivalents of $\left[\mathrm{Mo}(\mathrm{Mes})(\mathrm{CO})_{3}\right]$ to a solution containing 18-crown-6 (18C6) and $\mathrm{Na}_{2}\left[\mathbf{8}_{\mathbf{H f}}\right]$ in DCM yielded single crystals suitable for X-ray diffraction analysis. This species was identi- 


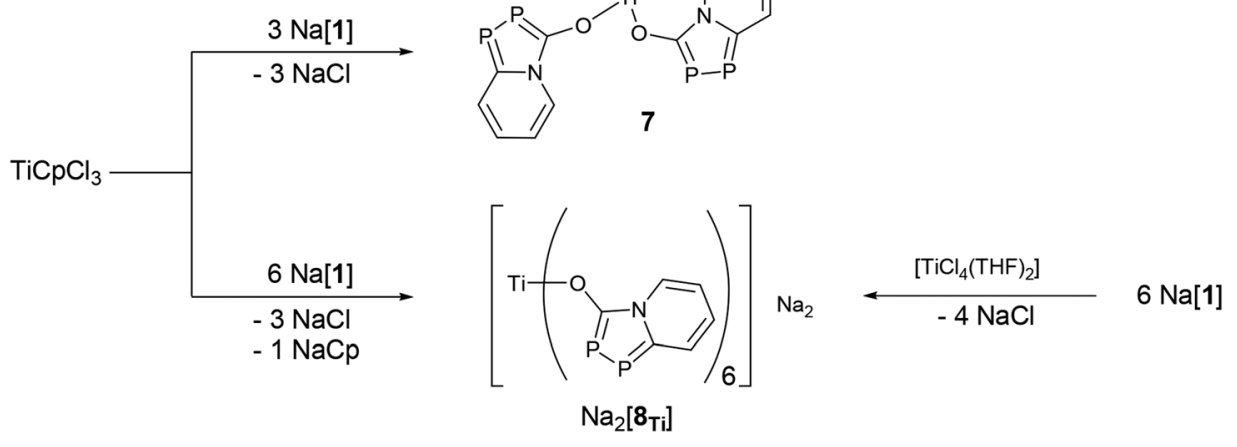

Scheme 2 Synthesis of compounds 7 and $\mathrm{Na}_{2}\left[8_{\mathrm{Ti}}\right]$.

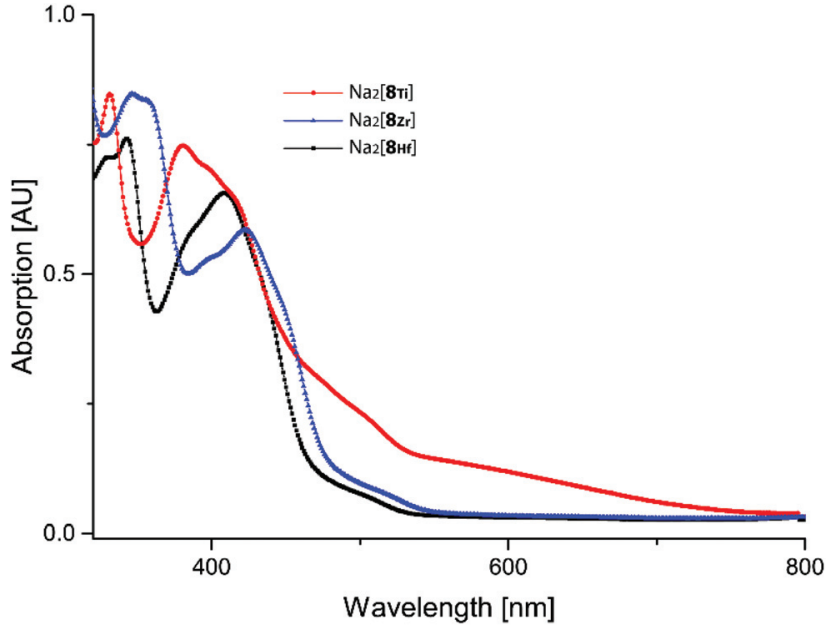

Fig. 3 UV-VIS absorption spectra of the complexes $\mathrm{Na}_{2}\left[\mathbf{8}_{\mathrm{Ti}}\right], \mathrm{Na}_{2}\left[\mathbf{8}_{\mathrm{Zr}}\right]$, $\mathrm{Na}_{2}\left[8_{\mathrm{Hf}}\right]$ in THF. The wavelength in $\mathrm{nm}$ is plotted against the absorption in arbitrary units.

fied as the trinuclear heterobimetallic complex $\mathrm{Na}_{2}\left[\mathbf{1 0}_{\mathbf{H f}}\right]$ which contains one $\mathrm{Hf}^{4+}$ in the center and two $\mathrm{Mo}(\mathrm{CO})_{3}$ units bound to the outer-sphere via the six phosphorus donor sites of the azadiphospholide units (Fig. 5). Once crystallized, compound $\mathrm{Na}_{2}\left[\mathbf{1 0}_{\mathbf{H f}}\right]$ is also only sparingly soluble in common organic solvents.

The three compounds 4 (Fig. 1), 7 and $\mathrm{Na}_{2}\left[\mathbf{8}_{\text {Ti }}\right]$ (Fig. 5) which do not contain a $\mathrm{Mo}(\mathrm{CO})_{3}$ fragment show similar characteristics in the solid state. The "hard" $\mathrm{P}(\mathrm{v})$ or Ti(Iv) centers are, as expected, bound to the oxygen atoms of the azadiphospholide unit which for steric reasons adopt a paddle wheel arrangement around the oxophilic centers. Upon complexation to $\mathrm{Mo}(\mathrm{CO})_{3}$, the azadiphospholide units are rotated inwards such that in every case the P1 centers form a tridentate pocket to which the $\mathrm{Mo}(\mathrm{CO})_{3}$ can bind in a facial fashion; that is every CO group is positioned trans to a P1 center. This feature can be seen in complexes 5 and $\mathrm{Na}[6]$ (Fig. 2). The coordination sphere around the molybdenum centers is

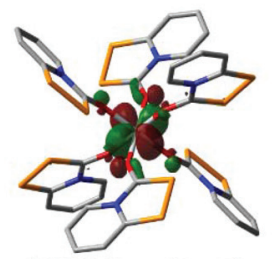

LUMO+1 (2.48)

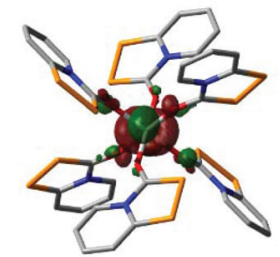

LUMO+1 (2.48)

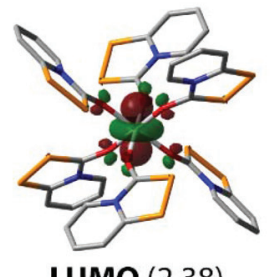

LUMO (2.38)
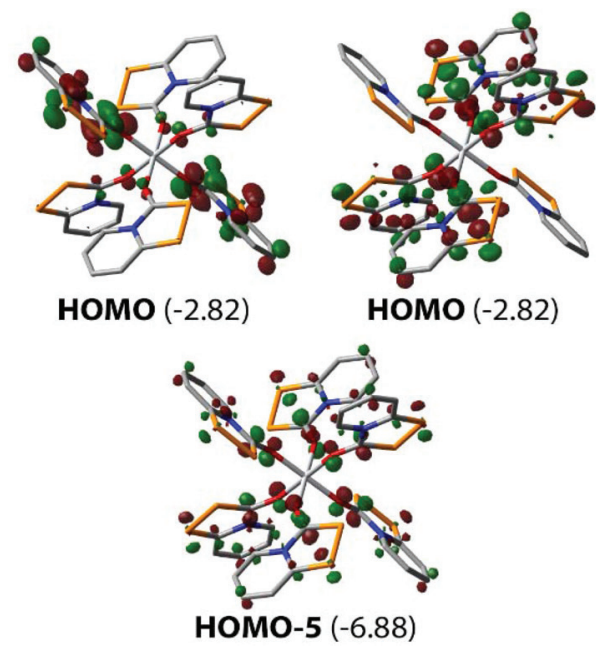

Fig. 4 Selected molecular orbitals of complex $\left[\mathbf{8}_{\mathrm{Ti}}\right]^{2-}$ which are involved in the absorption processes at low energies. Energies are given in $\mathrm{eV}$ and orbitals are depicted at an isovalue of 0.04 .

slightly distorted octahedral with Mo-P bond distances (Mo$\mathrm{P}_{\mathrm{av}} 2.475 \AA$ ) in the expected range. ${ }^{55}$ A comparison between the structures of 7 and 9 indicates that the structural parameters 
a)
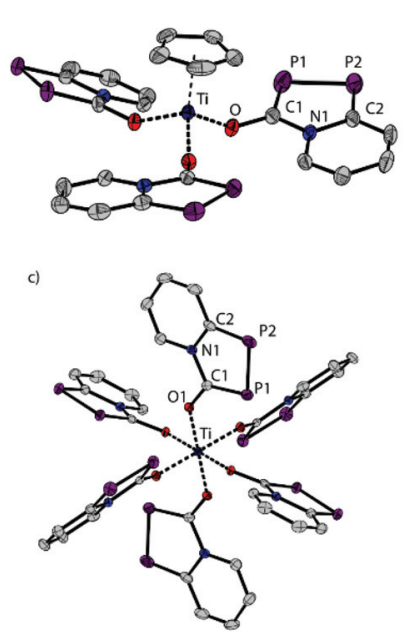

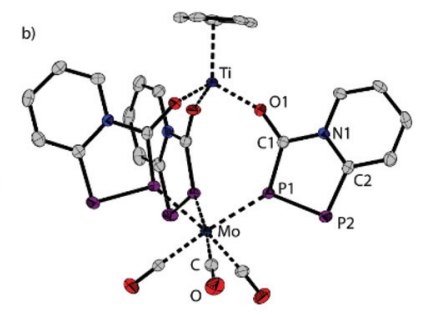

d)

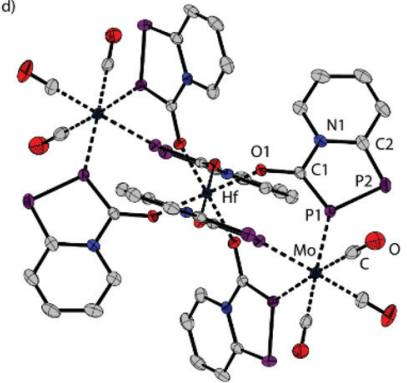

Fig. 5 Plots of the structures of (a): 7; (b): 9, (c): $\mathrm{Na}_{2}\left[8_{\mathrm{Ti}}\right]$, and (d): $\mathrm{Na}_{2}\left[10_{\mathrm{Hf}}\right]$. Anisotropic thermal displacement ellipsoids are shown at the $50 \%$ probability level. Hydrogen atoms, solvent molecules are omitted for clarity. The two sodium cations in $\mathrm{Na}_{2}\left[\mathbf{8}_{\mathrm{Ti}}\right]$ and $\mathrm{Na}_{2}\left[10_{\mathrm{Hf}}\right]$ are not shown. Average interatomic distances are summarized in Table 1.

of the azadiphospholide rings does not change significantly upon coordination to $\mathrm{Mo}(\mathrm{CO})_{3}$ and specifically the P1-P2 distance varies very little (7: 2.118 ̊̊; 9: $2.1029 \AA$ ).

The only remarkable structural differences between these complexes are associated with the $\mathrm{P} 1-\mathrm{C} 1, \mathrm{P} 2-\mathrm{C} 2$, and $\mathrm{C} 1-\mathrm{O} 1$ distances. In compounds $\mathbf{4}, \mathbf{5}$, and $\mathrm{Na}[\mathbf{6}]$, which do not contain a transition metal in the center, the $\mathrm{P} 1-\mathrm{C} 1$ bond adjacent to the C1-O1 group (av. 1.345 $\AA$ ) is in the range of 1.705-1.710 . This is significantly shorter than the $\mathrm{P} 2-\mathrm{C} 2$ bond (1.742-1.746 $\AA$ ). This feature is opposite to what is observed in the salt $\mathrm{Na}[\mathbf{1}]$ - with the "free" azadiphospholide anion where the P1-C1 bond $[1.760(3) \AA]$ is longer than the P2-C2 distance $[1.725(4) \AA]$ and the short C1-O1 bond $[1.268(3) \AA]$ indicates significant $\mathrm{C}-\mathrm{O}$ multiple bond character. ${ }^{52}$ In the compounds $7, \mathrm{Na}_{2}\left[\mathbf{8}_{\mathrm{Ti}}\right], \mathbf{9}$, and $\mathrm{Na}_{2}\left[\mathbf{1 0}_{\mathbf{H f}}\right]$ with a $\mathrm{M}(\mathrm{IV})$ center (M $=\mathrm{Ti}, \mathrm{Hf})$ the $\mathrm{P} 1-\mathrm{C} 1$ and $\mathrm{P} 2-\mathrm{C} 2$ bonds are almost equally long and the C1-O1 bond slightly shortened (1.302-1.332 ̊) with respect to 4,5 , and $\mathrm{Na}[\mathbf{6}]$. We attribute these effects to the more pronounced polarization of the $\mathrm{C}^{\delta+}-\mathrm{O} 1^{\delta-}$ bond which makes the azadiphospholide units in the Ti(Iv) and Hf(Iv) compounds more "anion like" such that adopt a structure which is closer to $[\mathbf{1}]^{-}$. The partial charge transfer from the azadiphospholide units to the $\mathrm{Ti}(\mathrm{IV})$, which is the reason for the red shifted long wave absorptions, is not reflected in the structural parameters. In all compounds containing $\mathrm{Mo}(\mathrm{CO})_{3}$ fragments, the distance between the Mo centers and the central atom is far above $4 \AA$ and excludes any electronic through space interactions.

In order to evaluate the electronic properties of the new tris(azadiphospholide) ligands $\mathrm{Na}[3], 4$ as well as the titanium compound 7 and hafnium derivative $\mathrm{Na}_{2}\left[\mathbf{8}_{\mathbf{H f}}\right]$, Table 2 lists the carbonyl stretching frequencies, $\nu_{\mathrm{CO}}\left[\mathrm{cm}^{-1}\right]$, of the $\mathrm{Mo}(\mathrm{CO})_{3}$
Table 2 IR frequencies in $\mathrm{cm}^{-1}$ for the carbonyl groups in the molybdenum metal complexes compared with literature known species

\begin{tabular}{lll}
\hline Compound & $\nu\left[\mathrm{cm}^{-1}\right]$ & $\nu\left[\mathrm{cm}^{-1}\right]$ \\
\hline $\mathrm{Mo}(\mathrm{CO})_{6}$ & 1967.1 & \\
{$\left[\mathrm{Mo}(\mathrm{Mes})(\mathrm{CO})_{3}\right]^{60}$} & 1973 & 1900 \\
{$\left[\mathrm{Mo}(\mathrm{triphos})(\mathrm{CO})_{3}\right]^{56}$} & 1930 & 1905 \\
{$\left[\mathrm{Mo}(\mathrm{PMe})_{3}(\mathrm{CO})_{3}\right]^{61}$} & 1923 & 1821 \\
{$\left[\mathrm{Mo}\left\{\mathrm{HB}(\mathrm{pyr})_{3}\right\}(\mathrm{CO})_{3}\right]^{-62}$} & 1897 & 1761 \\
$\mathbf{5}$ & 1960 & 1871 \\
{$[\mathbf{6}]^{-}$} & 1939 & 1844 \\
$\mathbf{9}$ & 1943 & 1863 \\
{$\left[\mathbf{1 0}_{\mathbf{H f}}\right]^{2-}$} & 1930 & 1817
\end{tabular}

complexes synthesized in this work. For comparison, the $\nu_{\mathrm{CO}}$ of a number of $\left[\mathrm{Mo}(\mathrm{L})_{x}(\mathrm{CO})_{3}\right]$ complexes including $\left[\mathrm{Mo}(\mathrm{CO})_{6}\right]$ are given. As expected, all complexes with a facial arrangement of the three CO groups show two $\nu_{\mathrm{CO}}$ stretching vibrations. Strongly $\sigma$-electron donating and poor $\pi$-accepting ligands like $\mathrm{PMe}_{3}$ or especially the anionic tris(pyrazolyl)borate shift the $\nu_{\mathrm{CO}}$ to lower wave numbers below $1900 \mathrm{~cm}^{-1}$ and $1800 \mathrm{~cm}^{-1}$, respectively, for the latter. Strong $\sigma$-donation increases the electron density at the Mo center which consequently increases the electron back donation in the $\pi^{*}$ orbital of the CO groups. On the contrary, a strong $\pi$-acceptor ligand like 1,3,5-tri(methyl) benzene (i.e. mesitylene $=$ Mes) diminishes the $\mathrm{M} \rightarrow \mathrm{CO}$ back donation and hence the $\nu_{\mathrm{CO}}$ increases. As Table 2 shows, the neutral tris(azadiphospholes) 2 and 7 have a smaller $\sigma$ donor: $\pi$-acceptor ratio when compared to phosphanes like $\mathrm{PMe}_{3}$ or triphos $\left(\mathrm{Me}-\mathrm{C}\left\{\mathrm{CH}_{2} \mathrm{PPh}_{2}\right\}_{3}\right){ }^{56}$ That is they behave as comparatively weaker $\sigma$-donors but stronger $\pi$-acceptors, a property which is well established for phosphinines, $\mathrm{PC}_{5} \mathrm{R}_{5}$, the phosphorus analogues of pyridines. ${ }^{57-59}$ As expected the monoanionic ligand $[3]^{-}$or dianionic ligand $\left[\mathbf{8}_{\mathbf{H f}}\right]^{2-}$ give the lowest $\nu_{\mathrm{CO}}$ in the series of complexes described in this paper and are coming very close to $\left[\mathrm{Mo}\left(\mathrm{PMe}_{3}\right)_{3}(\mathrm{CO})_{3}\right] \cdot{ }^{60}$ It is, however, remarkable that replacement of the PhSi group in $\mathbf{5}$ by the CpTi unit in 9 has a significant influence on $\nu_{\mathrm{CO}}$ and shifts the frequency $16 \mathrm{~cm}^{-1}$ to lower wavenumbers. This shows that the electron donation in the tridentate azadiphospholide ligands can be sensitively tuned by the remotely placed connecting node in the center of the ligand.

Finally, we studied the suitability of the azadiphospholide salt $\mathrm{Na}[\mathbf{1}]$ as building block for bidentate ligands. Earlier work showed that related alkoxy functionalized phosphinines ${ }^{63}$ react with chlorophosphanes, $\mathrm{R}_{2} \mathrm{PCl}$, to form such bidentate ligands which could be successfully used in the synthesis of photo-luminescent complexes. ${ }^{64,65}$ However, reactions of $\mathrm{Na}[\mathbf{1}]$ with chloro-phosphanes such as $\mathrm{PCl}_{3}, \mathrm{PhPCl}_{2}$ and $\mathrm{Ph}_{2} \mathrm{PCl}$ only formed brown insoluble precipitates. On the other hand, the reaction of $\mathrm{Na}[\mathbf{1}]$ with bis(diisopropylamino)chlorophosphane, $\left(\mathrm{iPr}_{2} \mathrm{~N}\right)_{2} \mathrm{PCl}$, proceeded cleanly to form compound $\mathbf{1 1}$ (Scheme 3). This substitution is accompanied by a colour change of the reaction mixture from orange to dark yellow and the precipitation of an off-white solid. ${ }^{31} \mathrm{P}\left\{{ }^{1} \mathrm{H}\right\}$ NMR spectroscopic analysis revealed the formation of one major product with three inequivalent phosphorus nuclei, forming a AMX 


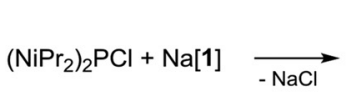

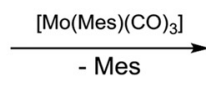

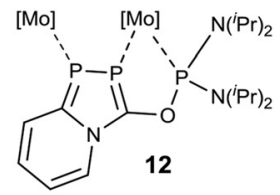

Scheme 3 Synthesis of 11 and the reaction with $\left[\mathrm{Mo}(\mathrm{Mes})(\mathrm{CO})_{3}\right]$ to form complex 12

spin system: ${ }^{31} \mathrm{P} \delta(\mathrm{ppm})=134.4\left(\mathrm{dd},{ }^{1} J_{\mathrm{P} 3, \mathrm{P} 1}=121.7 \mathrm{~Hz},{ }^{2} J_{\mathrm{P} 2, \mathrm{P} 3}\right.$ $=19.1 \mathrm{~Hz}), 121.7\left(\mathrm{dd},{ }^{1} J_{\mathrm{P} 2, \mathrm{P} 1}=425.6 \mathrm{~Hz},{ }^{2} J_{\mathrm{P} 2, \mathrm{P} 3}=19.1 \mathrm{~Hz}\right)$, $109.0\left(\mathrm{dd},{ }^{1} J_{\mathrm{P} 1, \mathrm{P} 2}=425.6 \mathrm{~Hz},{ }^{1} J_{\mathrm{P} 1, \mathrm{P} 3}=121.7 \mathrm{~Hz}\right)$. The coupling constant between the two phosphorus atoms in the azadiphosphole ring $\left(J_{\mathrm{PP}}=426 \mathrm{~Hz}\right)$ is comparable to the one in $\mathrm{Na}$ $[1]\left(J_{\mathrm{P}, \mathrm{P}}=424.7 \mathrm{~Hz}\right)$ indicating that the substitution took place at the oxygen atom. The coupling constant $J_{\mathrm{P} 1, \mathrm{P} 3}=121.7 \mathrm{~Hz}$ is relatively large for a ${ }^{3} J$-through bond coupling, and may be caused by the alignment of the two lone pairs at P1 and P3 causing a strong through space coupling. ${ }^{66}$ This assignment was supported by a structure determination through X-ray diffraction methods using a single crystal of $\mathbf{1 1}$ (Fig. 6).

In 11, the two phosphorus atoms P1 and P3 form a bidentate binding site (P1‥P3 $3.299 \AA$ ) which is ideally suited to bind a metal center in a $\kappa^{2}$-fashion. Furthermore, the phosphorus center P2 may bind to an additional metal center which opens the possibility of preparing multinuclear complexes. This idea was tested in the reaction of equimolar amounts of $\mathbf{1 1}$ and $\left[\mathrm{Mo}(\mathrm{Mes})(\mathrm{CO})_{3}\right]$ which upon loss of mesitylene opens up three coordination sites. Dark orange crystals were isolated directly from the reaction mixture after about 12 hours at room temperature and the product was analysed by X-ray diffraction analysis. Indeed, a tetranuclear molybdenum complex of the composition $\left[\mathrm{Mo}_{4}(\mathbf{1 1})_{4}(\mathrm{CO})_{12}\right](\mathbf{1 2})$ was formed (Fig. 7). Elemental analysis proved the purity of the compound, which is insoluble in all common deuterated solvents. The IR spectrum exhibits two major carbonyl bands at

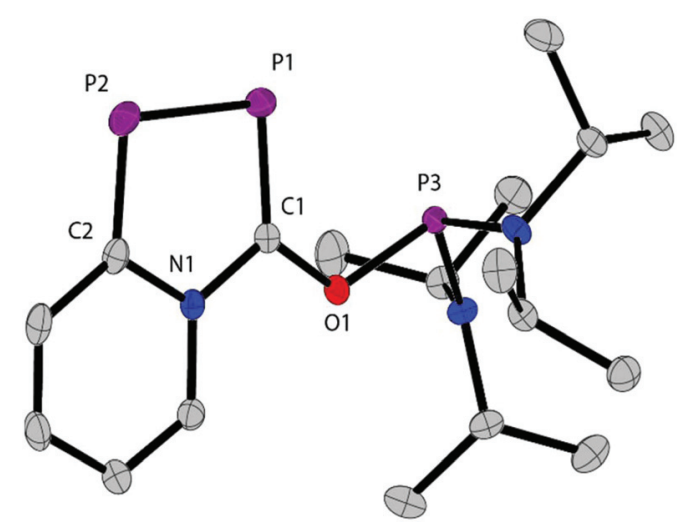

Fig. 6 Crystal structure of compound 11. Anisotropic thermal displacement ellipsoids are shown at the $50 \%$ probability level. Hydrogen atoms and the solvent molecules are omitted for clarity. Average interatomic distances (Å): P1 P2 2.1284(5), P2 C2 1.7373(15), P1 C1 1.7308(14), O1 C1 1.3496(16), N1 C1 1.3773(17), N1 C2 1.4074(17), P3 P1 3.299.
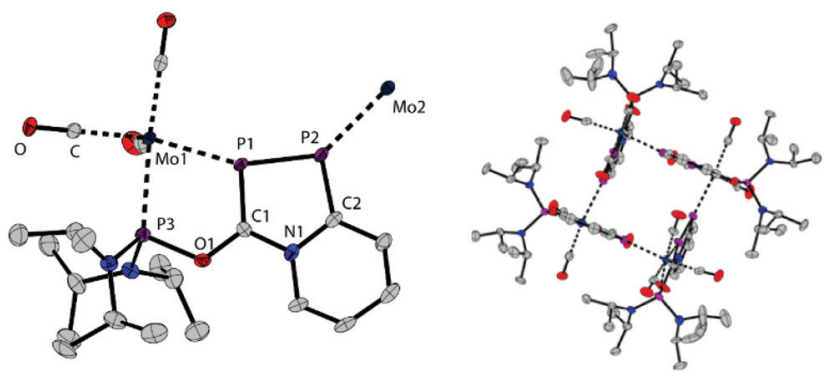

Fig. 7 Crystal structure of the organometallic macrocycle 12. Anisotropic thermal displacement ellipsoids are shown at the $50 \%$ probability level. Hydrogen atoms and three DCM molecules are omitted for clarity reasons. Average interatomic distances (Å): Mo1 P1 2.4816(17), Mo1 P3 2.5357(17), P2 Mo2 2.5042(15), P2 P1 2.100(2), P2 C2 1.740(7), P1 C1 1.722(7), C1 O1 1.347(8), C1 N1 1.372(9), C2 N1 1.397(8).

$\nu_{\mathrm{CO}}\left[\mathrm{cm}^{-1}\right]=1950,1849$ in the same range as observed in the complexes mentioned above.

Complex $\left[\mathrm{Mo}_{4}(\mathbf{1 1})_{4}(\mathrm{CO})_{12}\right]$ crystallizes in the orthorhombic space group $F d d 2$, with two azadiphosphole and molybdenum centers per asymmetric unit. The individual bond lengths and angles within the azadiphosphole units are comparable to the ones observed in the complexes discussed above. Upon coordination to Mo, the distance between the two phosphorus atoms P1 and P3 is slightly diminished to $3.132 \AA$. In the solid state, the $\left[\mathrm{Mo}_{4}(\mathbf{1 1})_{4}(\mathrm{CO})_{12}\right]$ macrocycles stack above each other such that channels with a diameter of about $5.6 \AA$ are formed (diagonal Mo-Mo distance $7.276 \AA$ A).

\section{Conclusions}

The salt $\mathrm{Na}[\mathbf{1}]$ containing the azadiphospholide anion is a versatile reagent for the synthesis of a range of new multidentate ligands. These are accessed via nucleophilic substitutions reactions with various main group and transition metal halides and in all cases studied so far, the "hard" oxygen center in $[\mathbf{1}]^{-}$ binds to the electrophilic center $\mathrm{E}$ in $\mathrm{R}_{n} \mathrm{ECl}_{m}(\mathrm{E}=\mathrm{B}, \mathrm{Si}, \mathrm{P}, \mathrm{Ti}$, $\mathrm{Zr}, \mathrm{Hf})$. The azadiphospholides form strongly coloured complexes with $\mathrm{d}^{0}$-titanium centers which is explained by LMCT excitations which indicate that the 1,3,4-azadiphospholes are rather electron rich heterocycles. The two adjacent phosphorus centers in the azadiphospholide ring possess each a lone pair of electrons which can be further engaged in the coordination to a transition metal center. This property was exploited in reactions $\left[\mathrm{Mo}(\mathrm{Mes})(\mathrm{CO})_{3}\right]$ and allowed to synthesize bi- and trinulecar heterobimetallic complexes. The reaction between 
$\left(\mathrm{iPr}_{2} \mathrm{~N}\right)_{2} \mathrm{PCl}$ and $\mathrm{Na}[\mathbf{1}]$ leads cleanly to a molecule with a $\mathrm{P}-\mathrm{O}-$ $\mathrm{C}-\mathrm{P}$ scaffold which is suitable as ligand for the synthesis of polynuclear macromolecular metalloheterocycles. In the crystalline state, these compounds from channels which eventually may be used for the encapsulation or adsorption of guest molecules. The preliminary results reported in this paper let hope that an especially rich coordination chemistry can be developed with these kind of polydentate phosphorus compounds which are moreover easily synthesized on a multi-gram scale.

\section{Conflicts of interest}

There are no conflicts to declare.

\section{Acknowledgements}

This work was supported by the ETH Zürich (project 0-2040618), and the Swiss National Science Foundation (SNF) (project 2-77199-18). Further support came from the NKFIH Grant (PD 116329), a Janos Bolyai Research Fellowship, and a UNKP Grant (UNKP-19-4-BME-422).

\section{Notes and references}

1 K. Itaya, I. Uchida and V. D. Neff, Acc. Chem. Res., 1986, 19, 162-168.

2 V. Balzani, A. Juris, M. Venturi, S. Campagna and S. Serroni, Chem. Rev., 1996, 96, 759-833.

3 R. C. Evans, P. Douglas and C. J. Winscom, Coord. Chem. Rev., 2006, 250, 2093-2126.

4 S.-i. Ohkoshi and H. Tokoro, Acc. Chem. Res., 2012, 45, 1749-1758.

5 L. M. C. Beltran and J. R. Long, Acc. Chem. Res., 2005, 38, 325-334.

6 J. T. Culp, J.-H. Park, F. Frye, Y.-D. Huh, M. W. Meisel and D. R. Talham, Coord. Chem. Rev., 2005, 249, 2642-2648.

7 R. Lescouëzec, L. M. Toma, J. Vaissermann, M. Verdaguer, F. S. Delgado, C. Ruiz-Pérez, F. Lloret and M. Julve, Coord. Chem. Rev., 2005, 249, 2691-2729.

8 J. S. Miller and J. L. Manson, Acc. Chem. Res., 2001, 34, 563-570.

9 M. Ohba and H. Ōkawa, Coord. Chem. Rev., 2000, 198, 313328.

10 M. Verdaguer, A. Bleuzen, V. Marvaud, J. Vaissermann, M. Seuleiman, C. Desplanches, A. Scuiller, C. Train, R. Garde, G. Gelly, C. Lomenech, I. Rosenman, P. Veillet, C. Cartier and F. Villain, Coord. Chem. Rev., 1999, 190-192, 1023-1047.

11 X. Y. Wang, Z. M. Wang and S. Gao, Chem. Commun., 2008, 281-294, DOI: 10.1039/b708122g.

12 S. Derossi, D. T. Farrell, C. J. Harding, V. McKee and J. Nelson, Dalton Trans., 2007, 1762-1772, DOI: 10.1039/ B617907J.
13 S. Pagano, G. Montana, C. Wickleder and W. Schnick, Chem. - Eur. J., 2009, 15, 6186-6193.

14 A. S. P. Frey, F. G. N. Cloke, M. P. Coles and P. B. Hitchcock, Chem. - Eur. J., 2010, 16, 9446-9448.

15 A. Escuer and G. Aromi, Eur. J. Inorg. Chem., 2006, 47214736, DOI: 10.1002/ejic.200600552.

16 J. G. Haasnoot, Coord. Chem. Rev., 2000, 200, 131-185.

17 G. Aromi, L. A. Barrios, O. Roubeau and P. Gamez, Coord. Chem. Rev., 2011, 255, 485-546.

18 M. Mlatecek, L. Dostal, Z. Ruzickova, J. Honzicek, J. Holubova and M. Erben, Dalton Trans., 2015, 44, 2024220253.

19 S. Trofimenko, Chem. Rev., 1993, 93, 943-980.

20 S. Trofimenko, Polyhedron, 2004, 23, 197-203.

21 A. Otero, J. Fernandez-Baeza, A. Antinolo, J. Tejeda and A. Lara-Sánchez, Dalton Trans., 2004, 1499-1510, DOI: 10.1039/b401425a.

22 V. Amendola, L. Fabbrizzi, F. Foti, M. Licchelli, C. Mangano, P. Pallavicini, A. Poggi, D. Sacchi and A. Taglietti, Coord. Chem. Rev., 2006, 250, 273-299.

23 J. M. Goicoechea and H. Grützmacher, Angew. Chem., Int. Ed., 2018, 57, 16968-16994.

24 A. R. Jupp and J. M. Goicoechea, Angew. Chem., Int. Ed., 2013, 52, 10064-10067.

25 F. F. Puschmann, D. Stein, D. Heift, C. Hendriksen, Z. A. Gal, H.-F. Grützmacher and H. Grützmacher, Angew. Chem., Int. Ed., 2011, 50, 8420-8423.

26 G. Becker, W. Schwarz, N. Seidler and M. Westerhausen, Z. Anorg. Allg. Chem., 1992, 612, 72-82.

27 M. Mehta, J. E. McGrady and J. M. Goicoechea, Chem. Eur. J., 2019, 25, 5445-5450.

28 D. W. N. Wilson and J. M. Goicoechea, Chem. Commun., 2019, 55, 6842-6845.

29 L. N. Grant, J. Krzystek, B. Pinter, J. Telser, H. Grützmacher and D. J. Mindiola, Chem. Commun., 2019, 55, 5966-5969.

30 L. Liu, D. A. Ruiz, F. Dahcheh, G. Bertrand, R. Suter, A. M. Tondreau and H. Grützmacher, Chem. Sci., 2016, 7, 2335-2341.

31 D. Heift, Z. Benkő and H. Grützmacher, Dalton Trans., 2014, 43, 5920-5928.

32 S. Alidori, D. Heift, G. Santiso-Quinones, Z. Benkő, H. Grützmacher, M. Caporali, L. Gonsalvi, A. Rossin and M. Peruzzini, Chem. - Eur. J., 2012, 18, 14805-14811.

33 D. W. N. Wilson, M. P. Franco, W. K. Myers, J. E. McGrady and J. M. Goicoechea, Chem. Sci., 2020, 11, 862-869.

34 Y. Mei, J. E. Borger, D.-J. Wu and H. Grützmacher, Dalton Trans., 2019, 48, 4370-4374.

35 L. N. Grant, B. Pinter, B. C. Manor, H. Grützmacher and D. J. Mindiola, Angew. Chem., Int. Ed., 2018, 57, 1049-1052.

36 R. J. Gilliard, D. Heift, Z. Benkő, J. M. Keiser, A. L. Rheingold, H. Grützmacher and J. D. Protasiewicz, Dalton Trans., 2018, 47, 666-669.

37 D. W. N. Wilson, A. Hinz and J. M. Goicoechea, Angew. Chem., Int. Ed., 2018, 57, 2188-2193.

38 K. M. Szkop, A. R. Jupp, R. Suter, H. Grützmacher and D. W. Stephan, Angew. Chem., Int. Ed., 2017, 56, 14174-14177. 
39 R. Suter, Y. B. Mei, M. Baker, Z. Benkő, Z. S. Li and H. Grützmacher, Angew. Chem., Int. Ed., 2017, 56, 13561360.

40 P. Coburger, H. Grützmacher and E. Hey-Hawkins, Chem. Commun., 2019, 55, 3187-3190.

41 J. Abbenseth, M. Diefenbach, A. Hinz, L. Alig, C. Würtele, J. M. Goicoechea, M. C. Holthausen and S. Schneider, Angew. Chem., Int. Ed., 2019, 58, 10966-10970.

42 G. Hierlmeier, A. Hinz, R. Wolf and J. M. Goicoechea, Angew. Chem., Int. Ed., 2018, 57, 431-436.

43 Y. Xiong, S. Yao, T. Szilvási, E. Ballestero-Martínez, H. Grützmacher and M. Driess, Angew. Chem., Int. Ed., 2017, 56, 4333-4336.

44 M. Joost, W. J. Transue and C. C. Cummins, Chem. Commun., 2017, 53, 10731-10733.

45 L. N. Grant, B. Pinter, B. C. Manor, R. Suter, H. Grützmacher and D. J. Mindiola, Chem. - Eur. J., 2017, 23, 6272-6276.

46 D. Heift, Z. Benkő, R. Suter, R. Verel and H. Grützmacher, Chem. Sci., 2016, 7, 6125-6131.

47 A. M. Tondreau, Z. Benkő, J. R. Harmer and H. Grützmacher, Chem. Sci., 2014, 5, 1545-1554.

48 D. W. N. Wilson, N. H. Rees and J. M. Goicoechea, Organometallics, 2019, 38, 4601-4606.

49 R. Magnall, G. Balázs, E. Lu, F. Tuna, A. J. Wooles, M. Scheer and S. T. Liddle, Angew. Chem., Int. Ed., 2019, 58, 10215-10219.

50 S. Bestgen, Q. Chen, N. H. Rees and J. M. Goicoechea, Dalton Trans., 2018, 47, 13016-13024.

51 C. Camp, N. Settineri, J. Lefèvre, A. R. Jupp, J. M. Goicoechea, L. Maron and J. Arnold, Chem. Sci., 2015, 6, 6379-6384.
52 R. Suter, Z. Benkő, M. Bispinghoff and H. Grützmacher, Angew. Chem., Int. Ed., 2017, 56, 11226-11231.

53 R. Suter, Z. Benkő and H. Grützmacher, Chem. - Eur. J., 2016, 22, 14979-14987.

54 K. A. Chernyshev and L. B. Krivdin, Russ. J. Org. Chem., 2011, 47, 355-362.

55 A. G. Orpen, L. Brammer, F. H. Allen, O. Kennard, D. G. Watson and R. Taylor, J. Chem. Soc., Dalton Trans., 1989, S1-S83, DOI: 10.1039/DT98900000S1.

56 J. Chart and H. R. Watson, J. Chem. Soc., 1961, 4980-4988.

57 Y. Hou, Z. Li, Y. Li, P. Liu, C.-Y. Su, F. Puschmann and H. Grützmacher, Chem. Sci., 2019, 10, 3168-3180.

58 C. Müller, L. E. E. Broeckx, I. de Krom and J. J. M. Weemers, Eur. J. Inorg. Chem., 2013, 2013, 187-202.

59 L. Nyulászi, Chem. Rev., 2001, 101, 1229-1246.

60 C. J. Breheny, J. M. Kelly, C. Long, S. O’Keeffe, M. T. Pryce, G. Russell and M. M. Walsh, Organometallics, 1998, 17, 3690-3695.

61 J. M. Jenkins, J. R. Moss and B. L. Shaw, J. Chem. Soc. A, 1969, 2796-2800, DOI: 10.1039/j19690002796.

62 S. Trofimenko, J. Am. Chem. Soc., 1969, 91, 588-595.

63 X. Chen, S. Alidori, F. F. Puschmann, G. Santiso-Quinones, Z. Benkő, Z. Li, G. Becker, H.-F. Grützmacher and H. Grützmacher, Angew. Chem., Int. Ed., 2014, 53, 1641-1645.

64 X. Chen, Z. Li and H. Grützmacher, Chem. - Eur. J., 2018, 24, 8432-8437.

65 X. Chen, Z. Li, F. Yanan and H. Grützmacher, Eur. J. Inorg. Chem., 2016, 2016, 633-638.

66 J.-C. Hierso, A. Fihri, V. V. Ivanov, B. Hanquet, N. Pirio, B. Donnadieu, B. Rebière, R. Amardeil and P. Meunier, J. Am. Chem. Soc., 2004, 126, 11077-11087. 